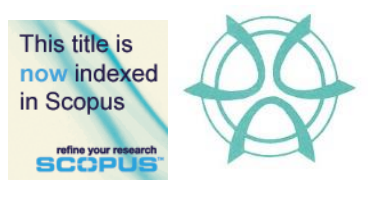

PLANNING MALAYSIA:

Journal of the Malaysian Institute of Planners

VOLUME 15 ISSUE 4 (2017), Page 127 - 138

\title{
UNDERSTANDING LOCAL AUTHORITY PERFORMANCE THROUGH ROLE THEORY
}

\author{
Sengboon Lim ${ }^{1}$, Jalaluddin Abdul Malek ${ }^{2}$, \& Zurinah Tahir ${ }^{3}$ \\ ${ }^{1,2,3}$ Faculty of Social Sciences and Humanities \\ UNIVERSITI KEBANGSAAN MALAYSIA
}

\begin{abstract}
Local government performance is frequently interpreted through stakeholders' satisfaction measured by statistical analyses. Apart from testing the relationship, the perception of satisfaction on services provided is further influenced by the degree of expectation being met, and understanding the customer behaviour. Thus, this study attempts to explore an alternative explanation on the character of the local authority (LA) and put in perspective through the comprehension of the role theory. This was an exploratory case study on Kulim Hi-tech Local Authority, Malaysia. The mixed method approaches were firstly carried out by questionnaire surveys, followed by interviewing stakeholders and ended with site observations. Descriptive analyses were applied to the random samples. Findings showed that the LA has executed its roles of control and collect very well. However, it did not fare well in the role of publish.
\end{abstract}

Keywords: Local Authority, Service Performance, Satisfaction, Behaviour, Role Taking

Date Received: $30^{\text {th }}$ June 2017

Date of Acceptance: $6^{\text {th }}$ November 2017 
Sengboon Lim, Jalaluddin Abdul Malek, \& Zurinah Tahir

Understanding Local Authority Performance Through Role Theory

\section{CURRENT RESEARCH BACKGROUND}

The function of local government is mainly on providing services to inhabitants resided within its administrated area and secondly, in development control. These broad ranges of services encompass public health and sanitation, waste removal and management, town planning, environmental protection and building control, and general maintenance of urban infrastructure and socio-economic development (Abdul Khalid, 2010). Supposedly in ideal situation, the local councils are to serve at their best in meeting citizens' needs and wants based on the power accorded by the Local Government Act 1976 (Act 171) and ensure that everyone is happy and satisfied with the councils' clear defined role and functions, effectiveness, caring, and prompt attendance on local issues. However, analysis of related literature indicates that in reality the majority of the citizens were found discontented (Bello, Martin \& Kasim 2017b; Zakaria et al., 2011; Zikri, Tarmiji \& Aziz, 2015), very few were revealed satisfied (Mansor \& Che Mohd Razali, 2010). These were due to many reasons such as the local government is under the 'state-list' and the State has direct financial powers to appoint councillors over the local government. Furthermore, most governmental expenditures on development are channelled through the Federal level ministries and statutory bodies such as the Urban Development Authority (UDA) and State Economic Development Corporation (SEDC). These lacking of financial autonomy issues were justified and suggestions were proposed even before the formation of the Act 171 (cf. Cheema \& Hussein, 1978; Nahappan Report, 1970); however, they have remained as challenges until today.

Most of the prior studies on local council's service performance were found to adopt statistical analyses to evaluate service performance to customer satisfaction (Mansor \& Che Mohd Razali; Zakaria et al., 2011; Zikri, Tarmiji \& Aziz, 2015; Bello et al., 2017a). For example, Zakaria et al. (2010) used Pearson correlation to test the hypothesis and conclude that there was a significant correlation between satisfaction and cleanliness, and proposed to increase better performance and more active collaboration with the stakeholders. In fact, such observation was vague. Thus, another aspect of analysis must be explored from the angle of human behaviour. Seeing that citizens are humans and their behaviour influences expectation, which mould their satisfaction towards the performance of the local council. Therefore, the socio-psychological aspect was missing in most of the previous assessments.

Hence, this study proposes the use of role theory to understand and assess the performance of local councils. Using role theory, the issue is viewed from the angle of the officers' behaviour, which reflects towards their customers. Role theory is an established social theory that elaborates deeply on human's characters (cf. Ojo \& Adedayo, 2017). Other than the psychological field, this theory has been applied widely in other fields, such as in service encounter 
PLANNING MALAYSIA

Journal of the Malaysia Institute of Planners (2017)

(Solomon et al., 1985), lecturer's role (Valk et al., 2014) and social media communicators (Carpenter \& Lertpratchya, 2016).

\section{PREDICTORS OF PERFORMANCE}

In the national political system, the local government lies on the third tier, which is the closest to the local population. To the population, the most important aspect of local councils is the service quality provided by the councils because it directly affects their lives. Thus, what are the predictors of performance that can be measured to satisfy the local inhabitants' need and wants? Prior studies indicate that these include service quality, public complaints, community development, law enforcement, environmental management, basic amenities, community health, street and light, cleanliness, employees' performance, layout of facilities, counter service quality, and size of council (Abdul Khalid, 2010; Joseph, 2010; Mansor \& Che Mohd Razali, 2010; Zakaria et al., 2011; Zikri, Tarmiji \& Aziz, 2015; Bello et al., 2017a).

In fact, the functional performance of the local government largely involves the regulation of the local affairs (Hazman \& Kalianan, 2008). Functional performances are expected roles, which are different from the private organisations. As pointed out by Alford and Speed (2006), cited in (Hazman \& Kalianan, 2008), local government do not always pursue to produce, supply and provide but also prevent, limit or shape consumption. Another issue to ponder is the mandatory and discretionary functions debated by some studies (Cheema $\&$ Hussein, 1978; Joseph, 2010; Nahappan Report, 1970; Zakaria et al., 2011). Mandatory functions are those critical functions that local councils are obligated to perform regardless of financial status such as refuse collection and activities pertaining to public health. Meanwhile, discretionary functions refer to other optional development functions such as providing amenities, housing and commercial activities. Nahappan Report (1970) proposes to include these divisions of functions in Act, so that local government will have more grant allocation in the national system. However, it remains an issue. Bearing in mind of these responsibilities, the possible predictors for this study were classified into four main predictors (verbs) thought as vital viz. control, collect, service, and publish.

The selection of predictors is not exhaustive as the first three predictors are basic functional responsibilities while the fourth is related to information dissemination, which is important in this information era. These four main predictors were further categorised into 15 sub-predictors as follows:

1. Expected role of control - land, building, industry and public spaces.

2. Expected role of collect - charges, taxes and fines.

3. Expected role of service - solid waste, drainage, landscape, street and lighting, and complaints. 
Sengboon Lim, Jalaluddin Abdul Malek, \& Zurinah Tahir

Understanding Local Authority Performance Through Role Theory

4. Expected role of publish - tenders and contracts, bulletins and statistics, and website.

\section{ROLE THEORY IN PERFORMANCE PERSPECTIVE}

The role theory is widely used in the behavioural study. Initially, in the 1930s, scholars like George Herbert Mead initiated the study on self, Robert Merton on social structure and Ralph Linton on man. These social ideas were later termed as the role theory by Biddle (1986) and others. Then again, what is the role and how is it related to this study? Turner (2001) conceives role as a pattern for behaviour, while Allen and van de Vliert (1984) view role as a behaviour referring to normative expectations associated with a position. This study adopts the definition by Biddle (1986, p. 67), whom explains roles by presuming that persons are members of social positions and hold expectations for their own behaviour and those of another person. The behavioural expectation is the key term in role theory. While Parsons (1991) views it as the norm, others see it as belief (Stryker, 2002) and also preference (Turner, 2001). In other words, behaviour is human characteristics, which stimulate expectation to a particular subject. In this study, the subject is the performance of local council. The result of the behavioural expectation is reflected in the degree of satisfaction perceived. Therefore, to enlighten the understanding of performance, the role theory was selected in this study as it was considered suitable and deeply related to behaviour expectation.

Prior to the discussion of performance, two related traditions, namely the symbolic interactionism and organizational role theory will be explained. In symbolic interactionism, the focus is on the individual actor socially interacting in a system that constitutes of shared norms. It is a micro-level theoretical framework in sociology that addresses how society is created and maintained through repeated interactions (Carter \& Fuller, 2015). Persons use language and significant symbols to disseminate information in their communications. This type of interactive communications between a service provider and customer is a reciprocal process rather than a linear one. According to Solomon et al., (1985), service experience which distinguishes one from another is a result of the unique interaction between an experienced and contact person.

In an organisational role theory, the attention shifts from individual to the organisations. Scholars focused their discussion on social systems that are preplanned, task-oriented, and hierarchical and discussed on employee performance and workplace behaviour as well as cost and conflict (Fisher \& Gitelson, 1983). This tradition also implies that organisations are rational and stable entities that all conflicts within them are merely role conflicts and that the participant will inevitably be productive once the role conflict is resolved (Biddle, 1986). Thus, a lot of role conflict articles come from this organisational tradition. Stryker and Macke (1978) point out that the reasons for conflict were due to stress, while 
PLANNING MALAYSIA

Journal of the Malaysia Institute of Planners (2017)

Rizzo, House and Lirtzman (1970) and Carpenter \& Lertpratchya (2016) studied on role conflict and ambiguity. Role conflict is the simultaneous occurrence of more role expectations such as compliance with one would make another more difficult (Katz \& Kahn, 1978). This opinion is related to this study, where LA holds multi-roles and tends to spark conflicts to others.

To put the discussion in perspective, the performances of local councils are influenced by four concepts, namely the controversial concept of role conflict, while the other three agreeable concepts were role taking, consensus, and conformity. The first concept was described in the previous paragraph. Meanwhile, the role taking concept refers specifically to every social position holder and represents expected behaviours (Katz \& Kahn, 1978). In the role holder behaviour, Neale and Griffin (2006) explain according to the model they created, which consists of self-concept (holder's own perception), system requirements (required by organizations and rules), and role schema (pre-existing expectations in a broader sense by society). The model by Neale and Griffin (2006, p.25) was found suitable in building role identity for LA. It creates a set of role clarity to stakeholders, thus, contributes to less conflict in the process of interacting with the public. The consensus construct refers to an agreement among the expectations that are held by various persons. In this concept, shared norms, preference, and beliefs in the social system are discussed as the crucial part to achieve consensus among all. To achieve consensus, consistency in doings and information is crucial. This leads to the last construct of conformity, which investigates the relationship between expectation and behaviour. Many scholars have assumed that conformity is good and social integration and personal satisfaction, are greater when persons obey their own and other's expectation (Biddle, 1986). If one does not know what is expected, (s)he will not know how to behave due to unclear evaluation standards (Carpenter \& Lertpratchya, 2016).

\section{METHOD}

This study used a random sample, where members of a population were selected one at a time, independent of one another and provided the ability to generalize a population (Creswell, 2014; Fowler, 2009). Kulim Hi-tech Local Authority was selected as the case study. Respondents were the stakeholders' viz. officers, residents, workers, and students. Non-stratified random sample method was applied in sample selection due to incomplete stakeholders' data in the Kulim Local Plan. Yamane formula and Israel's (1992, p.3) sampling table were used to guide the determination of sample size. For the population size of 59,000 (Lim, 2005 , p. 100), the size applied was 99 . This allows for the level of precision at $\pm 10 \%$, confidence level at $95 \%$, and maximum variability of $50 \%$ on the normal distribution population sample.

A mixed method was applied, firstly by quantitative (questionnaire) followed by qualitative (interview and site observation) methods. A set of semi- 
Sengboon Lim, Jalaluddin Abdul Malek, \& Zurinah Tahir

Understanding Local Authority Performance Through Role Theory

structured questionnaire was developed, consisting of three parts. Particularly, part II is on the assessment of the predictors by using a 10-point scale ranging from very poor to very excellent. Interviews were conducted after respondents filled up the surveys. In-depth interviews were carried out on officers in order to verify data and challenges faced. Finally, the data collected were analysed using descriptive statistics, namely percentage and mean score via SPSS v21, and explained through role theory.

The mean score (MS) of each indicator was grouped into five categories, namely the poor category with MS 0 to 1.9 , low with MS 2.0 to 3.9, moderate with MS 4.0 to 5.9, good with MS 6.0 to 7.9, and the category of excellent with MS 8.0 to 10 (cf. Rahimi et al., 2013, p. 1151).

\section{FINDINGS}

\section{Demography of the Respondent}

In general, the respondents of this study ranged from 19 to 70 years old, where the majority were youths, ranging from 15 to 40 years old, male, locals, staying inside the Kulim Hi-Tech Park, three to nine years of dwelling history, professionals, and serving in private sector (refer Table 1).

Table 1 Respondents Profile, total 99 samples

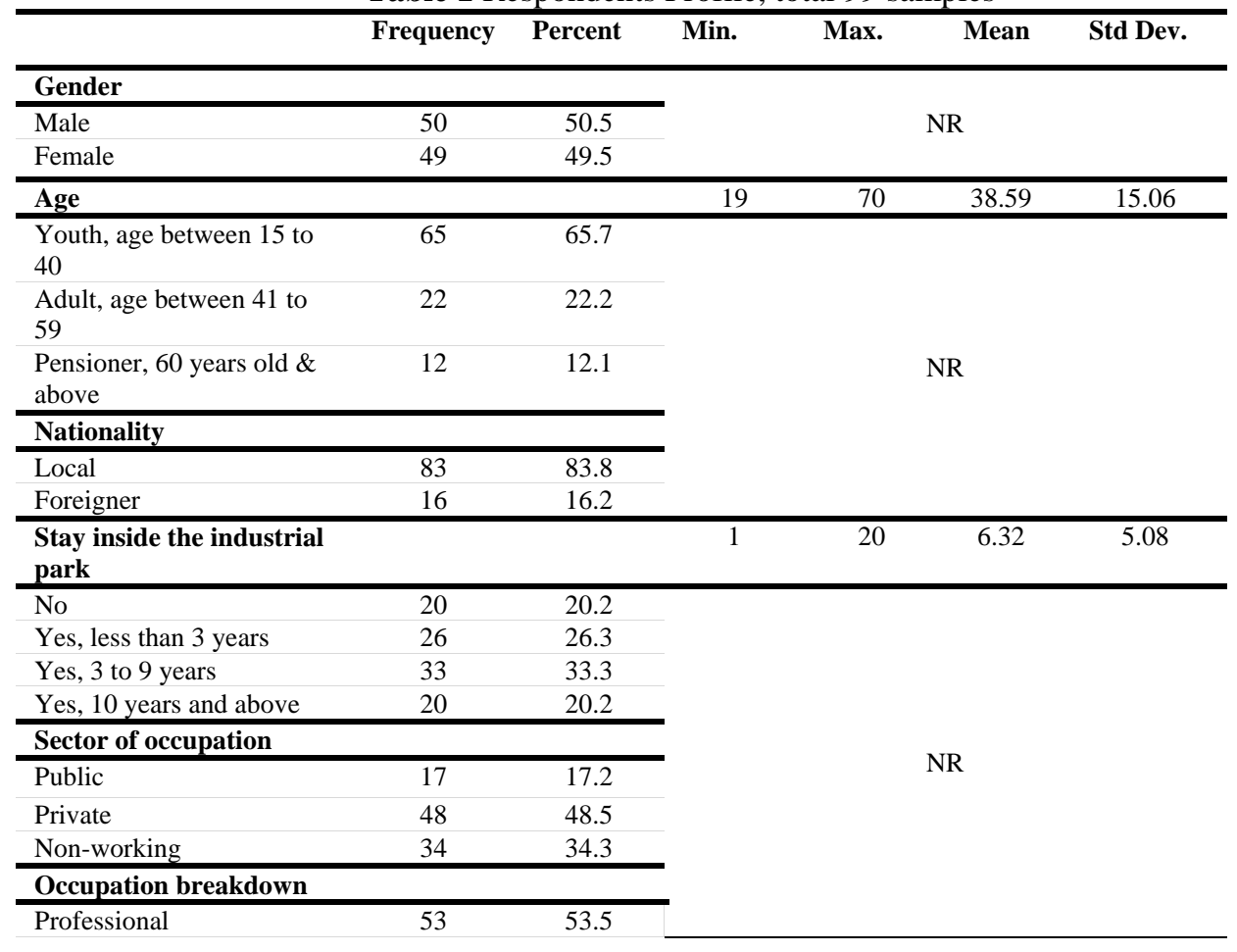


PLANNING MALAYSIA

Journal of the Malaysia Institute of Planners (2017)

\begin{tabular}{lcc} 
Non professional & 12 & 12.1 \\
Student & 19 & 19.2 \\
Housewife & 5 & 5.1 \\
\hline Pensioner & 10 & 10.1 \\
\hline Using LA's website & & \\
\hline No & 67 & 67.7 \\
\hline Yes & 32 & 32.3 \\
\hline Understanding LA's role & & \\
\hline No & 35 & 35.4 \\
Yes & 64 & 64.6 \\
\hline
\end{tabular}

* NR- Not related

Source: The authors, 2017

\section{The Mean Score Analysis}

Among the major roles, control received the highest score of 6.37 (based on the average mean scores of four sub-predictors of controls), which is in the range of 'good'. The other three predictors were only 'moderate', where collect received MS of 5.53, service 5.22, and publish 4.37 (refer Figure 1). No roles were considered by respondents as in either the poor or excellent range.

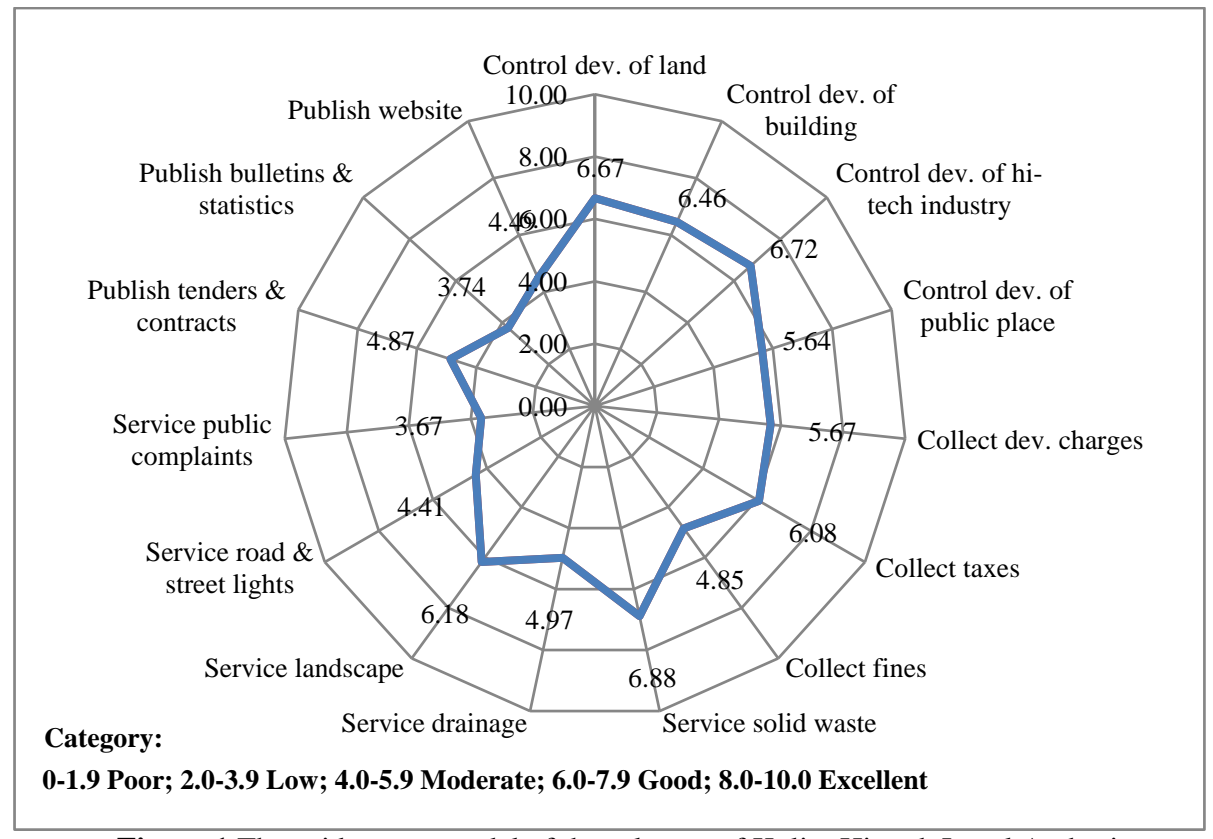

Figure 1 The spidergram model of the role sets of Kulim Hi-tech Local Authority Source: The authors, 2017

In detailing the sub-role set of control, LA plays a significant role in controlling the development of land, building, industry and public places. Based on the interview, the planning officer identified limited development land as an 
Sengboon Lim, Jalaluddin Abdul Malek, \& Zurinah Tahir

Understanding Local Authority Performance Through Role Theory

issue faced by LA, while an architect respondent was satisfied with the one week respond of plan approval. On the pollution issue, there was no major complaint and LA seemed to have coordinated well with the environmental department. In terms of public places, site observations showed that the recreational park and roadsides were green, clean and tidy. A corporate officer mentioned that there was a newly built sports centre to provide space for leisure.

In the second role of collect, LA showed moderate ability in managing its financial affairs, where taxes received MS of 6.08, charges 5.67 and fines 4.85. According to the finance officer of the LA, only $70 \%$ of assessment taxes were paid. The reasons for not paying include land sub-division issue, unaffordability and also LA failed to contact premise owner. To reduce tax arrears, LA issued warning and followed by 'red notice'. This has been effective in collecting $10 \%$ of the arrears.

On the third role of service, solid waste received the highest satisfaction from survey whereas public complaints were recorded as in the least satisfied. From the interview, there were complaints where respondents urged LA to take action on the issue of foreigners renting houses in the area without control, leading to safety threats. Some respondents were also not satisfied with council's responses or actions since there seemed to be too little change even after complaints were lodged.

On the fourth role of publish, the sub-predictors received moderate and low MS between 3 to 4. During the site visits, only two leaflets about recycling and tax refund were at the service counter. In terms of the website, despite being published since 2007, it received low number of visitors averaging only 180 visitors per day. According to the council's IT officer, efforts were made to gradually update the website such as by adding functions to allow visitors to check payment status on taxes. However, many sub-pages were blank of information viz. the latest news, and community and programs. Results also indicated that the role of publish received least attention from the LA compared to the other three roles.

\section{DISCUSSION ON SPIDERGRAM}

Based on the mean score, a spidergram was formulated (refer Figure 1). Based on the spidergram, it can be concluded that the LA service performance is moderate skewing towards good. This means that the LA has executed its role consciously, was accepted in a certain degree of inconsistency among the officers and satisfied most of the requirements by the stakeholders. However, LA also faces conflicts in terms of service and publish role expectations. The two roles viz. collect and publish are potential for LA to leap towards excellent position and being free from all conflicting expectations in the future. This is because, once financial income is adequate and the strategies of disseminating information through various publication channels are sound, LA will gain public conformity 
PLANNING MALAYSIA

Journal of the Malaysia Institute of Planners (2017)

and confidence. These can be achieved through changes in behaviour, i.e., increase seriousness towards building good governance image. LA must also be quick to inform the public of any major decisions as this assists in gaining conformity from the public (Carpenter \& Lertpratchya, 2016).

Conflicts also exist in the role of collect. According to Biddle (1986), the limit of achieving normative consensus may appear to be integrated into the mass media or the imposition of power. In this case, LA was suggested to exercise its power and inform through mass media or by giving notice. This instrumental type of conformity is effective as persons who conform are also likely to grow status or idiosyncrasy credits for their actions (Stryker, 2002).

For the role of service, the consensus on solid waste and landscape services were good. However, severe conflicts and low position also occurred in handling public complaints and servicing road lights. These negative impacts of role stress can be mitigated by several organisational interventions such as developing conflict management skills, job redesign, empowerment, and socialisation programs (Valk et al., 2014, p. 103-104). Various empowerment programs will definitely help in mitigating role stress to create participation from the public (Hazman \& Kalianan, 2008). In terms of manpower, currently the LA has 37 staff and only five are permanent. Similar to the finding by Cheema and Hussein (1978), the study also discovered that lack of permanent human capital is critical to administration. To close the gap of citizens' expectation, LA is proposed to increase the number of permanent staff. The suggested governmentcitizen model by Hazman and Kalianan (2008) is a factor to consider where LA may empower citizens in certain projects gradually. As more civic engagement are involved, it is believed that both role holder and recipients will be sharing accountabilities and beliefs, thus contributing to public consensus.

Last but not least, the current skewed low position of the role of publish is viewed as a potential area to embark on and eventually push the whole MS rating up to excellent. Publication is a powerful tool in symbolic interaction in building a vibrant identity. It is crucial to project a good governance identity. The LA is also suggested to respond promptly to public complaints, and to strategically share their beliefs, norms and preferences with the general public. This is one of the measures to improve the LA's identity among the public. The costs of projecting such identity can be planned wisely through publications.

\section{CONCLUSION}

This research is an exploratory study of the stakeholders' view to explain the quantitative results presented in spidergram using role theory. This attempt of using the role theory in explaining the performance of LA has filled the gap in studying the public organisation role from the socio-psychological point of view. This study also implied that organizational leaders need to re-evaluate public expectations, utilise publication tools, and provide attentive behaviour towards 
Sengboon Lim, Jalaluddin Abdul Malek, \& Zurinah Tahir

Understanding Local Authority Performance Through Role Theory

citizens' need and wants, as well as means to arrive at the mutual consensus status. The selection of predictors and the spidergram presentation served the purpose of forming the performance scripts in understanding the role of public organisations. The agreement on norms, beliefs, and preferences set by LA will be easier to perceive and allow normative conformity from the public when these expectations are shared strategically through participating initiatives. Future research may modify the method to include the ethnographic approach or changing the target respondent to the public organization leaders and exploring the role theory in related to staff-behaviour in articulating their tasks and communications within the expected functions.

\section{ACKNOWLEDGEMENT}

We would like to express sincere thanks to those who have contributed ideas, comments or assistances, namely Er Ah Choy, Daramora Japheth, Aizul Fidy Kamarudin, Rusyda Ramly, Rosni Ramli, Munauwarah Ziauddin and anonymous reviewers.

\section{REFERENCES}

Allen, V. L., \& van de Vliert, E. (1984). Role transitions: Explorations and explanations. New York: Plenum.

Biddle, B. J. (1986). Recent developments in role theory. Annual Review of Sociology, 12, 67-92.

Carpenter, S., \& Lertpratchya, A. (2016). A qualitative and quantitative study of social media communicators: An extension of role theory to digital media workers. Journal of Broadcasting \& Electronic Media, 60(3), 448-464.

Carter, M. J., \& Fuller, C. (2015). Symbolic interactionism. Sociopedia.isa, (1), 117.

Cheema, G. S., \& Hussein, S. A. (1978). Local government reform in Malaysia. Asian Survey, 18(6), 577-591.

Creswell, J. W. (2014). Research design: Qualitative, quantitative, and mixed methods approaches (4th Ed.). UK: Sage Publications.

Fisher, C. D., \& Gitelson, R. (1983). A meta-analysis of the correlates of role conflict and ambiguity. Journal of Applied Psychology, 68(2), 320-333.

Fowler, F. J. (2009). Survey research methods (4th Ed.). Thousand Oaks, CA: Sage.

Hazman, S. A. \& Kalianan, M. (2008). From customer satisfaction to citizen satisfaction: Rethinking local government service delivery in Malaysia. Asian Social Science, 4(11), 87-92.

Israel, G. D. (1992). Determining sample size. Fact Sheet PEOD-6, 1-5.

Joseph, C. (2010). Sustainability reporting on Malaysian local authority websites (Doctorate Thesis). Curtin University of Technology.

Katz, D., \& Kahn, R. L. (1978). The social psychology of organizations (2nd Ed.). New York: Wiley. 
Lim, S. B. (2005). A comparative study of technology firms in Tsukuba Science City, Japan and Kulim Hi-Tech Park, Malaysia (Master's Thesis). Universiti Teknologi Malaysia.

Bello, M. U., Martin, D., Kasim, R., Abubakar, M., \& Umar, M. A. (2017a). An examination of relationship between quality municipal services and citizen satisfaction in Malaysian local council, Batu Pahat in perspective. Path of Science, 3(5), 2.1-2.4.

Bello, M. U., Martin, D., \& Kasim, R. (2017b). Municipal awareness as a tool for enhancing citizen satisfaction in municipal councils of Malaysia. European Journal of Social Sciences Studies, 2(5), 109-121.

Nahappan Report. (1970). Report of the royal commission of enquiry to investigate into the workings of local authorities in West Malaysia. Kuala Lumpur: National Printers

Neale, M., \& Griffin, M. A. (2006). A model of self-held work roles and role transitions. Human Performance, 19(1), 23-41.

Mansor, N., \& Che Mohd Razali, C. H. (2010). Customers' satisfaction towards counter service of local authority in Terengganu, Malaysia. Asian Social Science, 6(8), 197-208.

Ojo, J. O., \& Adedayo, S. O. (2017). Analysis of some selected theories applicable to consumer behaviour research. Pyrex Journal of Business and Finance Management Research, 3(4), 112-120.

Parsons, T. (1991). The social system (2nd Ed.). London: Routledge.

Rahimi, A., Che Sobry, A., Norlena, H., Shahimi, M., \& Nur Hasni, O. (2013, March). The impact of technology parks services on the high technology industry: A case study on Kulim Hi-Tech Park. 20th IBIMA Conference, March 25-26, Kuala Lumpur, Malaysia.

Rizzo, J. R., House, R. J., \& Lirtzman, S. I. (1970). Role conflict and ambiguity in complex organizations. Administrative Science Quarterly, 15(2), 150-163.

Abdul Khalid, S. N. (2010). Improving the service delivery: A case study of local authority in Malaysia. Global Business Review, 11(1), 65-77.

Solomon, M. R., Surprenant, C., Czepiel, J. A., \& Gutman, E. G. (1985). A role theory perspective on dyadic interactions: The service encounter. Journal of Marketing, 49(1), 99-111.

Stryker, S. (2002). Traditional symbolic interactionism, role theory, and structural symbolic interactionism. In J. H. Turner (Ed.), Handbook of Sociological Theory (pp. 211-231). New York: Kluwer Academic/ Plenum Publishers.

Stryker, S., \& Macke, A. S. (1978). Status inconsistency and role conflict. Annual Review of Sociology, 4, 57-90.

Turner, R. H. (2001). Role Theory. Handbook of Sociological Theory. Springer US.

Valk, A., Järvet, S., Kratovitš, M., \& Aron, S. (2014). Insights into the public defence speciality lecturer's roles in the institution of professional higher education and the controversial role expectations in developing their professional identity. In Proceedings of Estonian Academy of Security Sciences 2014 (pp. 95-118). Tallinn, Estonia: Sisekaitseakadeemia. 
Sengboon Lim, Jalaluddin Abdul Malek, \& Zurinah Tahir

Understanding Local Authority Performance Through Role Theory

Zakaria, Z., Ngah, N., Mustaffa, J., Noordin, N., \& Mohamed Sawal, M. Z. H. (2011) Public satisfaction in local authorities: A case study in Kedah. International Review of Social Sciences and Humanities, 1(2), 46-54.

Zikri, M., Tarmiji, M., \& Aziz, A. M. (2015). Local government service efficiency: public participation matters. International Journal of Social Science and Humanity, 5(10), 827-831. 